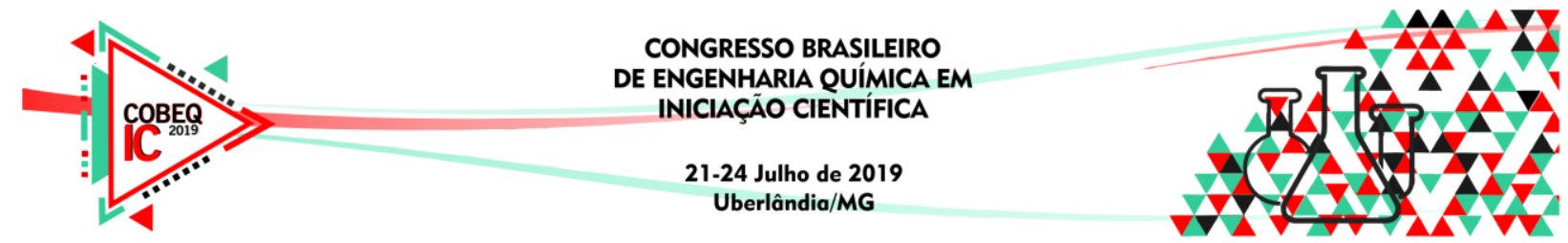

\title{
Desenvolvimento de procedimento determinativo para análise quantitativa de níquel em cachaças de alambique de cobre empregando espectrofotometria UV-VIS.
}

\author{
A. M. MUCHON ${ }^{1}$, K. M. LIMA ${ }^{1}$ e A. M. ALMEIDA ${ }^{2}$ \\ ${ }^{1}$ Centro Universitário de Formiga, Bacharelado em Engenharia Química \\ ${ }^{2}$ Centro Universitário de Formiga Docente Responsável \\ E-mail para contato: alexmuchon@gmail.com
}

\begin{abstract}
RESUMO - O elemento níquel vem sendo usado e ingerido pelo ser humano desde tempos imemoriais, seja em meio a ligas metálicas ou em micro quantidades nos alimentos ingeridos. Em se tratando de um metal considerado pesado, sua presença em excesso no corpo humano pode vir a ocasionar enfermidades, doenças ou intoxicações decorrentes de sua ação peculiar no organismo, como a redução da função pulmonar, bronquite crônica e asma, entretanto, é sempre necessário uma avaliação cientifica para tais constatações. Neste trabalho desenvolveu-se um procedimento com diversas especificações para realizar uma análise quantificada e precisa do elemento em cachaças consumidas na região do centro-oeste mineiro. As análises realizadas indicam que o metal está presente em todas as amostras avaliadas. Todos os parâmetros utilizados para avaliar quanto a toxidade da cachaça, neste trabalho, foram baseados em estudos canadenses, devido à falta de informações a nível nacional.
\end{abstract}

\section{INTRODUÇÃO}

O níquel (Ni) é o $24^{\circ}$ metal em abundância na crosta terrestre, caracterizado como metal pesado, apresentando $\mathrm{d}=8,5 \mathrm{~g} / \mathrm{cm}^{3}$. Na forma metálica é branco prateado, dúctil e maleável, possui grande resistência à corrosão e oxidação pelo ar, água e agentes alcalinos e por estes motivos é muito utilizado na composição de ligas metálicas. Dentre os vários compostos, os principais são óxido de níquel $(\mathrm{NiO})$, hidróxido de níquel $(\mathrm{NiOH})$, sulfeto de níquel $\left(\mathrm{Ni}_{3} \mathrm{~S}_{2}\right)$ e cloreto de níquel $\left(\mathrm{NiCl}_{2}\right)$. Os sais de níquel provenientes de ácidos orgânicos fortes são solúveis em água, enquanto os oriundos de ácidos inorgânicos fracos são insolúveis. (AZEVEDO, CHASIN, 2003). Segundo o Instituo de Metais Não Ferrosos (ICZ, 2019), o níquel é encontrado como microelemento no corpo humano e tem função vital em ativar ou inibir diversas reações enzimáticas que são consideradas de importância crucial e de acordo com o sistema de saúde do Canadá, a população teria um consumo médio diário de $308 \mu \mathrm{g} / \mathrm{dia}$ em se tratando do que for ingerido por meio da alimentação. Há ainda fatores que devem ser levados em consideração para constatar uma possível intoxicação e/ou doença causada pelo níquel, os quais devem ser o meio no qual o individuo teve contato com o metal, tempo de exposição, frequência e concentração do mesmo. Em estudos ligados a saúde humana, foi constatado que certos compostos contendo níquel podem levar atividade 


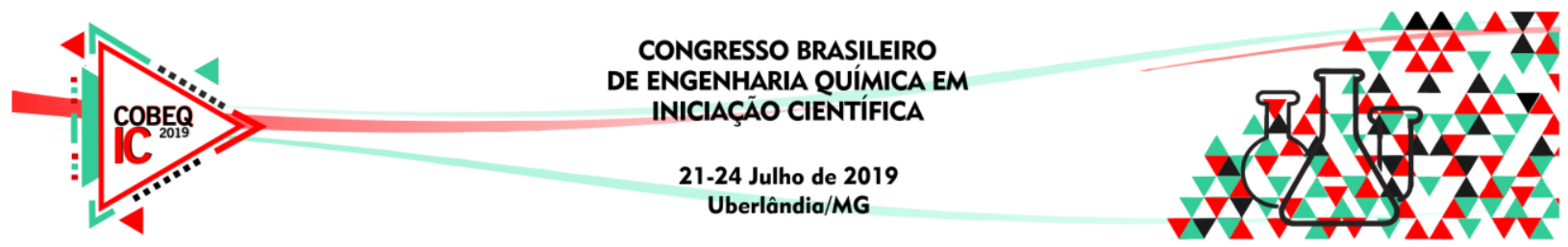

carcinogênica (JUNIOR, 2014), compostos insolúveis, como sulfeto de níquel II (NiS), óxido de níquel $(\mathrm{NiO})$ e sulfeto de níquel $\left(\mathrm{Ni}_{3} \mathrm{~S}_{2}\right)$, não são facilmente removidos dos tecidos e, por isso, são mais carcinogênicos do que compostos solúveis como acetato de níquel $\left(\mathrm{Ni}(\mathrm{OAc})_{2}\right)$, cloreto de níquel $\left(\mathrm{NiCl}_{2}\right)$ e sulfato de níquel $\left(\mathrm{NiSO}_{4}\right)$ (DENKHAUS; SALNOKOW, 2002). O níquel foi classificado no nível mais perigoso das substâncias cancerígenas, no grupo 1, porém não há provas suficientes em animais ou seres humanos sobre qual exposição que provoca o câncer. (CLANCY, COSTA, 2012; SEO, KIM, RYU, 2005). Foram realizados ainda estudos em piercings, joias, broches, dentre outros materiais que contêm parcelas de níquel em sua composição, constatando em pessoas mais sensíveis ao contato casos de dermatite e outras reações. Estudos tanto in vivo como in vitro demonstram que o níquel altera diferentes níveis de regulação do sistema neuroendócrino de mamíferos. O metal induz a alteração da prolactina e dos níveis de LH (hormônio luteinizante). Os resultados indicam que as alterações hormonais são os principais causadores da toxicidade à reprodução, tanto no nível endócrino como nas gônadas. Observou-se que o níquel $\left(\mathrm{Ni}^{2+}\right)$ é capaz de imitar a hipóxia, pois pode conduzir à ativação de algumas vias de sinalização e a transcrição dos fatores, o que, eventualmente, resultará na alteração da expressão do gene e do metabolismo celular. Consequentemente, eis a base da gênese da toxicidade reprodutiva e da carcinogenicidade (FORGACSA, et al., 2012, QAYYUM, et al., 2012). Em um estudo com 356 mulheres que trabalhavam em uma refinaria de níquel no Ártico russo, constatou-se que houve maior taxa de abortos espontâneos $(15,9 \%)$ em comparação com a taxa correspondente a 342 mulheres locais que não trabalhavam na planta (8,5\%). Ratos expostos ao sulfato de níquel sofreram degeneração testicular (KAS, DAS, DHUNDASI, 2008). Mesmo diante de vários embasamento científicos e teórico, ainda a muito que se desconhece quanto ao metal e suas reações nos seres vivos, vale ainda ressaltar que no Brasil não existem valores de segurança por órgãos governamentais na dosagem em alimentos ou bebidas, mesmo assim ainda são feitos diversos estudos em função de averiguar um fator de risco ou não. Este trabalho objetiva o desenvolvimento de um procedimento para a identificação e quantificação do metal níquel em cachaças de alambique de cobre.

\section{DESENVOLVIMENTO}

Visando a detecção do elemento níquel nas cachaças desenvolveu-se um procedimento para a determinação espectrofotométrica UV-VIS, utilizando dimetilglioxima, reagente específico para o metal, solubilizada em dimetilformamida na concentração $0,861 \mathrm{~mol} / \mathrm{L}$. Desta forma, foram realizadas varreduras entre 300 e $600 \mathrm{~nm}$ de acordo com o Gráfico 1, onde pode-se vislumbrar o comprimento de onda característico para o composto. A partir deste aspecto, realizou-se o desenvolvimento da curva de calibração conforme o Gráfico 2 e um estudo dos componentes para obter um sistema ideal entre reagente metálico e complexante consonante a Tabela 1. Durante o estudo foi concebido a possibilidade de haver metais que disputassem a interação química entre o reagente dimetilglioxima e o níquel, fator o qual foi estudado de acordo com as possíveis interações reagente/metal. Após um estudo de interferentes por meios bibliográficos e experimentais constatou-se que os elementos Paládio $(\mathrm{Pd})$, Rênio ( $\mathrm{Re})$ e Ferro $(\mathrm{Fe})$ poderiam causar competitividade com o reagente estipulado, entretanto foi constada a ausência de Ferro nas cachaças analisadas e devido a raridade de Paládio e Rênio na natureza e no próprio dia a dia de um alambique conclui-se que não haveria a necessidade de preocupação ou dúvida dos resultados obtidos ou quanto a sua veracidade. 
Gráfico 1 - Varredura para o metal níquel complexado com dimetilglioxima em solução de dimetilformamida, contra um branco do reagente.

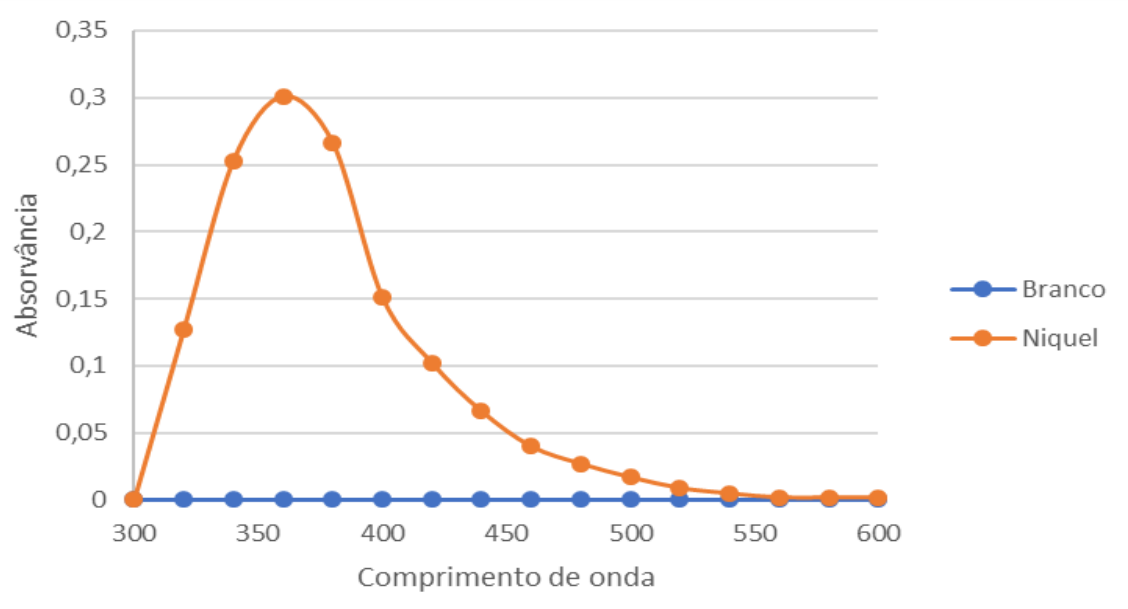

Gráfico 2 - Curva de calibração.

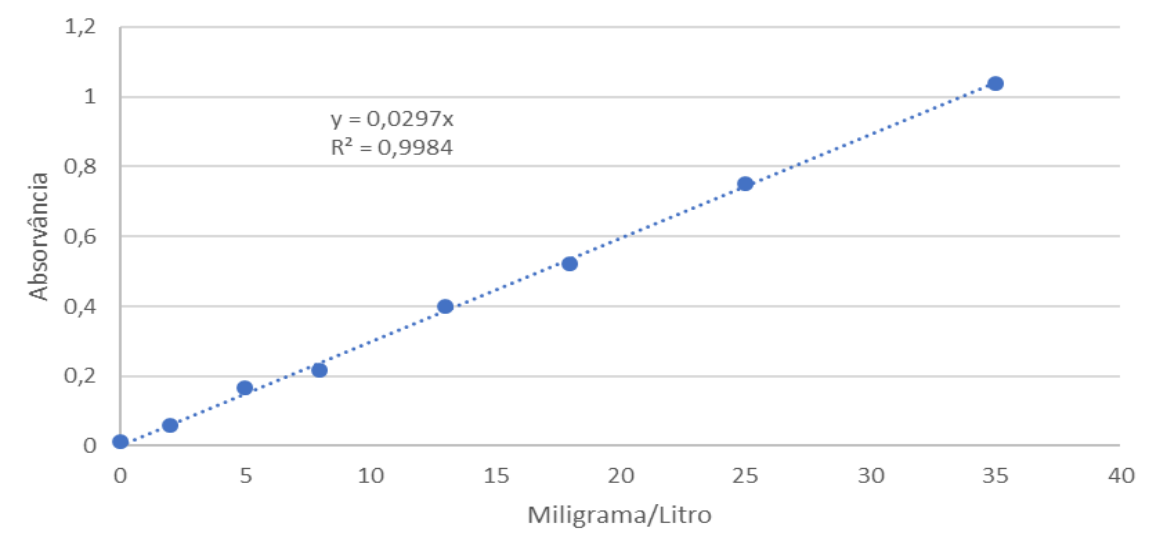

Tabela 1 - Estudo do sistema ideal de complexação.

\begin{tabular}{|c|c|c|}
\hline Água (mL) & Dimetilglioxima (mL) & Absorvância \\
\hline 1 & 9 & 0,035 \\
\hline 2 & 8 & 0,07 \\
\hline 3 & 7 & 0,1 \\
\hline 4 & 6 & 0,132 \\
\hline 5 & 5 & 0,15 \\
\hline 6 & 4 & 0,187 \\
\hline 7 & 3 & 0,144 \\
\hline 8 & 2 & - \\
\hline 9 & 1 & - \\
\hline
\end{tabular}




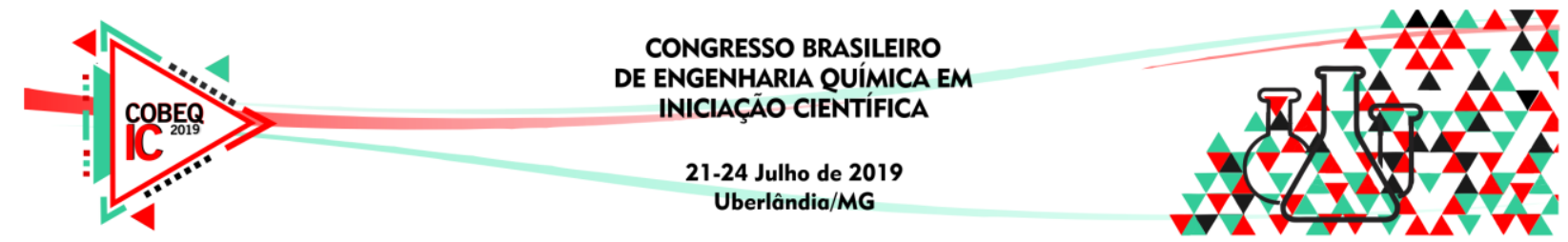

O estudo demonstrou que o sistema ideal é obtido pela utilização de $6 \mathrm{~mL}$ de amostra em conjunto com $4 \mathrm{~mL}$ de complexante devido ao fato que alterando os valores de água superiores ao dimetilglioxima, a amostra inicia um processo de formação de material particulado no meio em função da ausência de complexante necessário e/ou excesso de metal.

\section{RESULTADOS}

Após a realização dos estudos necessários para o desenvolvimento do método em questão, efetuaram-se análises em 5 marcas de cachaças do centro-oeste mineiro como pode ser observado na Tabela 2. Todas as cachaças são fabricadas em alambiques de cobre, e não passaram por processo de envelhecimento em qualquer tipo de recipiente secundário, o que nos leva a crer que não sofreram interferência do meio externo, o qual poderia levantar dúvida quanto as análises.

Todas passaram pelo mesmo processo de estudo, o qual envolveu a realização de triplicata real, tendo assim os seguintes resultados nas condições de leitura:

Tabela 2- Resultados obtidos para a quantificação de níquel nas cachaças avaliadas.

\begin{tabular}{|c|c|c|c|c|c|}
\hline \multirow{2}{*}{ Cachaças } & \multicolumn{3}{|c|}{ Absorvância à 360 nm } & \multirow{2}{*}{ [Ni] mg/L } \\
\cline { 2 - 5 } & Amostra 1 & Amostra 2 & Amostra.3 & Média & \\
\hline $\begin{array}{c}\text { Alambique } \\
\text { de [Cu] 1 }\end{array}$ & 0,304 & 0,303 & 0,292 & 0,300 & 10,01 \\
\hline $\begin{array}{c}\text { Alambique } \\
\text { de [Cu] 2 }\end{array}$ & 0,191 & 0,208 & 0,224 & 0,208 & 6,88 \\
\hline $\begin{array}{c}\text { Alambique } \\
\text { de }[\mathrm{Cu}] \text { 3 }\end{array}$ & 0,071 & 0,045 & 0,057 & 0,058 & 1,78 \\
\hline $\begin{array}{c}\text { Alambique } \\
\text { de [Cu] 4 }\end{array}$ & 0,055 & 0,058 & 0,043 & 0,052 & 1,57 \\
\hline $\begin{array}{c}\text { Alambique } \\
\text { de [Cu] 5 }\end{array}$ & 0,097 & 0,128 & 0,114 & 0,113 & 3,65 \\
\hline
\end{tabular}

\section{CONSIDERAÇÕES FINAIS}

De acordo com os resultados obtidos e por conta de a via de ingestão do material ser oral, as quantidades de níquel evidenciadas nas cachaças não apresentam risco a saúde de curto a longo prazo, considerando-se apenas a ingestão de cachaça. O elemento metálico é facilmente expelido pelo organismo nas formas de urina, suor e cabelos, e até os tempos atuais não foram constatadas enfermidades, doenças ou intoxicação proveniente do mesmo quando ingerido junto a alimento ou bebidas. 


\section{REFERÊNCIAS BIBLIOGRÁFICAS}

AZEVEDO, F. A.; CHASIN, A. M. Metais Gerenciamento da toxicidade. Belo Horizonte: Atheneu, 2003. 554 p.

CLANCY, H., COSTA, M. (2012). Nickel: A pervasive carcinogen. Future Oncology, 8, 1507-1509. doi:10.2217/fon.12.154

DENKHAUS, E. SALNOKOW, K. Nickel essentiality, toxicity, and carcinogenicity. Critical Reviews in Oncology/Hematology, v.42, p35 - 56, 2002.

JUNIOR, Jose de Felippe. Os metais como causadores de doenças. Revista da Sociedade Brasileira de Medicina Biomolecular e Radicais Livres. 2014, http://www.medicinacomplementar.com.br/biblioteca/pdfs/Biomolecular/mb0755.pdf. Acesso em 12/03/2019.

GONZALEZ, Karina Regina. Toxicologia do Níquel. Revista Intertox de Toxicologia Risco Ambiental e Sociedade, v. 9, n. 2, p. 30-54, jun. 2016.

QAYYUM, S.; ARA, A.; USMANI, J. A. Effect of nikel and chromium exposure on bucal cells of electroplaters. Toxicol In Health, 28(1):74-82, 2012.

KAS, K., DAS, S., DHUNDASI, S. (2008). Nickel, its adverse health effects and oxidative stress. Indian Journal of Medical Research, 128, 412-425. 